\title{
Dívida pública, poupança em conta corrente do governo e superávit primário: uma análise de sustentabilidade
}

\author{
ALEXANDRE MANOEL ANGELO DA SILVA \\ MANOEL CARLOS DE CASTRO PIRES*
}

Public debt, government current account saving and primary surplus: analysis of sustainability. On this paper, we propose a change in the primary surplus' target by the government current account saving. That concept excludes public investment from primary surplus. However, of that change has raised a question about if government current account saving represents a sustainable fiscal policy. Thus, this paper analyses if the change in the primary surplus' target by the government current account saving implies a meaning modification on the debt-to-GDP ratio path. The empirical analysis, which is based on Brazilian monthly data for the period 1999-2005, suggests that the change in fiscal target does not mean a lack of sustainability.

Keywords: primary surplus; debt-to-GDP ratio; government current account saving.

JEL Classification: H62; H63; H69.

\section{INTRODUÇÃO}

No período anterior à implementação do Plano Real, período marcado por elevadas taxas de inflação, a literatura econômica aplicada aponta que as receitas com senhoriagem são fundamentais para manter a sustentabilidade da dívida pública brasileira (Rocha, 1997); Issler \& Lima 2000). Durante um curto período, após a implementação do Plano Real e o conseqüente declínio das taxas de infla-

\footnotetext{
*Técnicos em Planejamento e Pesquisa do IPEA. E-mails: Alexandre@ipea.gov.br e manoel.pires@ipea. gov.br. Agradecemos aos valiosos comentários de Fernando M. Gonçalves, Luiz de Mello, Marcelo Caetano e Marcelo Piancastelli. Erros remanescentes são de nossa inteira responsabilidade. Submetido: Março 2006; Aprovado: Outubro 2006.
} 
ção, as receitas com as privatizações compensaram as receitas originadas nas altas taxas de inflação (Gremaud, Vasconcelos \& Toneto Jr., 2005).

Em seguida à substancial diminuição nas receitas oriundas de privatizações e ao início do regime de câmbio flutuante, ${ }^{1}$ o governo brasileiro forçosamente iniciou seu ajuste fiscal. Nesse sentido, nos últimos anos, percebe-se uma elevação na rigidez orçamentária ${ }^{2}$ e uma deterioração no volume de investimento público, ${ }^{3}$ o qual diminuiu em prol da obtenção dos maiores níveis de superávits primários. ${ }^{4}$ Diante desse arcabouço institucional, vários testes têm sido aplicados para analisar a sustentabilidade da dívida pública brasileira.

Ao aplicar o teste proposto por Wilcox (1989), na análise do período entre janeiro de 1995 e dezembro 2002, Giambiagi \& Ronci (2004) indicaram que a dívida líquida real do setor público consolidado brasileiro é insustentável. Ao inspecionar o período compreendido entre dezembro de 1997 e junho de 2004 e utilizar três outros testes (Hakkio \& Rush, 1991; Bohn, 1991 e Bohn (1998), Bicalho (2005) aponta sustentabilidade da razão dívida pública/PIB e infere a característica spend-and-tax da política fiscal no Brasil, i.e., mostra uma expansão simultânea do gasto e da receita no setor público brasileiro.

Ao estimar funções de reação fiscal, com base em Bohn (1998), no período de janeiro de 1995 a julho de 2004, e realizar testes de co-integração, no período de janeiro de 1998 a julho de 2004, Mello (2005) confirma as análises de sustentabilidade da dívida pública e spend-and-tax encontradas em Bicalho (2005). Desse modo, na literatura econômica aplicada ao Brasil, parece iniciar-se um consenso na direção da sustentabilidade da dívida pública no período posterior à implementação do Plano Real.

Entretanto, até mesmo economistas preocupados com a sustentabilidade da dívida pública brasileira, como Afonso, Amorim \& Biasoto Jr. (2005), sugerem que a política fiscal de maiores superávits primários obtidos por meio da redução do investimento público representa um óbice ao crescimento econômico, implicando, pois, a necessidade de equacionar-se a manutenção da vigente austeridade fiscal com o aumento dos investimentos públicos. ${ }^{5}$

\footnotetext{
${ }^{1}$ Os dados do BCB mostram que, em 1997, a dívida líquida do setor público consolidado foi de 34,3\% do PIB, enquanto, em maio de 1999, quatro meses depois da implementação do regime de câmbio flutuante, passou para $50,1 \%$ do PIB.

${ }^{2}$ Segundo estudo técnico do MP/SOF (2003) em 1997, as despesas de livre alocação (discricionárias) da União representavam aproximadamente $22 \%$, enquanto, em 2003 , somente cerca de $11 \%$ das despesas da União eram discricionárias.

${ }^{3}$ Conforme os dados do MF/STN, em 1998, acumulado em 12 meses, o investimento do setor público consolidado foi de 4,22\% do PIB, enquanto, em 2004, esse investimento foi de 3,54\% do PIB.

${ }^{4}$ De acordo com os dados do BCB, em 1998, acumulado em 12 meses, o déficit primário do setor público consolidado foi de $0,01 \%$ do PIB, enquanto, em 2004, esse setor público obteve um superávit primário de 4,59\% do PIB.
}

${ }^{5}$ Almeida \& Pessoa (2006) sugerem, ainda, que, em virtude de comprometer o crescimento do PIB, a 
Nesse sentido, em vez de testes de sustentabilidade da dívida pública no presente arcabouço institucional, propõe-se, neste estudo, uma alteração na atual política fiscal, de modo a manter a austeridade fiscal e elevar o nível de investimento público, ou seja, em consonância com Blanchard \& Giavazzi (2004), propõe-se permutar a meta fiscal embasada no superávit primário pela meta de poupança em conta corrente do governo. O conceito de poupança em conta corrente do governo consiste na retirada dos investimentos públicos do cálculo do superávit primário. Em virtude de não penalizar a elevação do estoque de capital, um dos determinantes do crescimento econômico, o conceito de poupança em conta corrente do governo mostra-se economicamente mais adequado do que o superávit primário.

De maneira precisa, conceitua-se poupança em conta corrente do governo da seguinte forma: total de tributos subtraídos dos gastos correntes (custeio, transferências correntes/capital e inversões financeiras). Esse conceito difere do resultado primário tão-somente porque exclui o investimento público líquido de seu cálculo. Ou seja, ao não se considerar o investimento público líquido no cálculo do resultado primário, obtém-se a poupança em conta corrente do governo. Dessa forma, quando o investimento é realizado por critérios econômicos, os investimentos das estatais e das administrações diretas e indiretas federal, estadual e municipal devem ser excluídos do cálculo do resultado primário, pois o fluxo dos rendimentos dos ativos adquiridos é superior ao fluxo de pagamentos derivados do financiamento desses ativos.

Cabe, portanto, a seguinte pergunta no Brasil por que é importante estabelecer a poupança em conta corrente do governo em vez do superávit primário como meta fiscal? Em primeiro lugar, no Brasil, o superávit primário é obtido por meio de aumento da carga tributária e do represamento do investimento público. Ademais, é consensual entre os economistas que os investimentos públicos, sobretudo em infra-estrutura, ${ }^{6}$ não podem ser adiados indefinidamente sob pena de representar um gargalo para o crescimento econômico. Nesse sentido, em virtude de o superávit primário criar os incentivos para que os gestores públicos cortem os investimentos ${ }^{7}$ nas consecuções das limitações de movimentação financeira para alcançar a meta fiscal e por acreditar em que os investimentos públicos, sobretudo em infra-estrutura, realizados por critérios econômicos não é igual a zero, viabiliza-se a utilização do conceito de poupança em conta corrente do governo.

Em segundo lugar, a poupança em conta corrente do governo gera os incentivos corretos para que se eleve a atual taxa de investimento, pois alguns estudos empíricos realizados para o Brasil mostram uma complementaridade positiva entre investimento público e privado.

elevação de superávit primário com redução de investimento público possui, no médio prazo, impacto ambíguo sobre a relação dívida pública/PIB.

${ }^{6}$ Afonso, Amorim \& Biasoto Jr. (2005).

${ }^{7}$ Segundo estudo técnico do MP/SOF (2003), em 2003 apenas aproximadamente $11 \%$ das despesas da União eram discricionárias, as quais, em sua maioria, eram constituídas de investimentos. 
Apesar dos ganhos citados, uma questão que circunda a permuta do superávit primário pela poupança em conta corrente do governo é se a utilização dessa poupança não significa muito mais um relaxamento fiscal do que propriamente uma mudança de política justificada pela teoria econômica. Assim, torna-se válido avaliar essa proposta do ponto de vista da sustentabilidade fiscal.

Nesse intuito, além desta introdução, o artigo está estruturado em quatro seções. Na próxima seção, a fim de evidenciar a proposição teórica de permuta da meta de superávit primário pela de poupança em conta corrente do governo, introduzse o modelo proposto por Blanchard \& Giavazzi (2004). Na seção 3, constroem-se, a partir da análise econométrica, cenários que sugerem que a implementação dessa permuta pode elevar a taxa real de crescimento do PIB, sem prejudicar a austeridade fiscal implementada pelo governo brasileiro desde 1999. Na seção 4, discutem-se duas questões práticas referentes à implementação do conceito de poupança em conta corrente do governo. Por fim, na seção 5, apresentam-se algumas conclusões.

\section{SUPERÁVIT PRIMÁRIO VERSUS POUPANÇA EM CONTA CORRENTE DO GOVERNO}

Em uma análise da política fiscal, um dos indicadores utilizados para verificar a sustentabilidade do endividamento público é a razão dívida pública/PIB ao longo do tempo $\left(\frac{B_{t}}{P I B_{B}}-\frac{B_{t-1}}{P I B_{t}}\right)$. Em tese, ao supor-se que o déficit primário $\left(G_{t}-T_{t}\right)$ seja nulo, a evolução intertemporal dessa razão é equivalente à diferença entre a taxa real de juros $(r)$ e a taxa real de crescimento do $\operatorname{PIB}^{8}(n)$.

$$
\frac{B_{t}}{P I B_{t}}-\frac{B_{t-1}}{P I B_{t-1}}=(r-n) \frac{B_{t-1}}{P I B_{t-1}}-\frac{G_{1}-T_{t}}{P I B_{t}}
$$

Caso a taxa real de juros seja menor que a taxa real de crescimento do PIB, a razão dívida pública/PIB é declinante ao longo do tempo. Nesse cenário, não há espaço para problematizar a questão da sustentabilidade do endividamento público. Se a taxa real de juros for maior que a taxa real de crescimento econômico, tem-se uma razão dívida pública/PIB crescente ao longo do tempo. Nesse caso, a fim de evitar uma explosão nessa razão, torna-se necessário implementar superávit primário $\left(G_{1}<T_{t}\right)$, o qual possui sua magnitude definida em função do tamanho que se objetiva para a relação dívida pública/PIB.

Ao observar a economia brasileira, percebe-se que a diferença entre a taxa real de juros e a taxa real de crescimento do PIB correlaciona-se positivamente com a magnitude da razão dívida pública/PIB. Uma possível conjectura para a causalidade dessa correlação é a seguinte: quanto maior é a razão dívida pública/

\footnotetext{
${ }^{8} \mathrm{Na}$ equação 1 , assim como nas outras equações derivadas nesta seção, utiliza-se a seguinte proposição: $\frac{1+r}{1+n} \approx(1+r-n)$ e ignora-se a receita com senhoriagem, em virtude de sua substancial diminuição no período pós-Plano Real.
} 
PIB, maior é a taxa real de juros exigida pelos rentistas9. Por sua vez, quanto maior é a taxa real de juros, menor é o incentivo ao investimento privado, deteriorando, assim, o crescimento do PIB. Além disso, como a estrutura orçamentária do setor público brasileiro é bastante rígida, os maiores superávits primários são construídos também às expensas do investimento público, o que deteriora ainda mais a taxa real de crescimento do PIB.

Em se tratando de análise da sustentabilidade intertemporal da trajetória da razão dívida/PIB, o superávit primário mostra-se substancialmente um conceito contábil, de modo que, neste artigo, defende-se o mesmo ponto de vista de Blanchard \& Giavazzi (2004), ${ }^{10}$ os quais sustentam ser mais apropriado excluir o investimento público líquido do cálculo do superávit primário, a fim de alcançar melhorias na estabilidade e no pacto de crescimento da União Européia.

Em consonância com Blanchard \& Giavazzi (2004), ao considerar-se o investimento público $\left(I_{t}\right)$, os gastos correntes $\left(G C_{t}\right)$, a taxa bruta financeira de retorno do capital público $(\vartheta)$ e o estoque de capital público $(K)$, tem-se a seguinte restrição orçamentária do governo:

$$
\frac{B_{t}}{P I B_{t}}-\frac{B_{t-1}}{P I B_{t-1}}=(r-n) \frac{B_{t-1}}{P I B_{t-1}}+\frac{G C_{1}-T_{t}}{P I B_{t}}+\frac{I_{t}}{P I B_{t}}-\vartheta \frac{K_{t}}{P I B_{t}}
$$

É válido destacar que, de forma geral, $\vartheta<r$. Ou seja, geralmente a taxa de retorno financeiro é menor do que o custo de financiamento do projeto. No entanto, nos casos em que a externalidade social é superior à externalidade privada, diz-se que a taxa de retorno social do projeto governamental é superior ao custo de financiamento. Nesse caso, apesar de os cálculos financeiros não recomendarem o investimento público, este deve ser realizado, pois os ganhos de eficiência são evidentes.

A fim de retirar algumas relações da equação (2), adota-se a regra de orçamento equilibrado. Em outras palavras, quando o PIB estiver próximo ao valor do PIB potencial, tem-se

$$
r \frac{B_{t-1}}{P I B_{t-1}}+\frac{G C_{1}-T_{t}}{P I B_{t}}+\frac{I_{t}}{P I B_{t}}-\vartheta \frac{K_{t}}{P I B_{t}}=0
$$

tal que

$$
\frac{B_{t}}{P I B_{t}}-\frac{B_{t-1}}{P I B_{t-1}}=n \frac{B_{t-1}}{P I B_{t-1}}
$$

\footnotetext{
${ }^{9}$ Ao utilizarem uma amostra de 50 países, incluindo o Brasil, Gonçalves, Holland \& Spacov (2005) concluem que, em vez do binômio incerteza jurisdicional-inconvertibilidade do câmbio sugerido por Arida, Bacha \& Lara-Resende (2004), o que se correlaciona positiva e estatisticamente de forma significativa com a taxa real de juros é a razão dívida pública/PIB.

${ }^{10} \mathrm{~A}$ proposta desses autores baseia-se em uma antiga proposição de finanças públicas, a qual sugere a separação do orçamento em orçamento corrente e orçamento de capital. Ver Musgrave (1939).
} 
Como é usual no cálculo dos custos econômicos das firmas, suponha que se incluam entre os gastos governamentais apenas os referentes à manutenção e ao funcionamento da máquina administrativa, os quais podem ser evidenciados por meio dos gastos correntes $\left(G C_{t}\right)$, da depreciação e dos custos de manutenção do capital público, que são representados pela taxa de manutenção do capital público $(\delta)$, e que não se incluam os investimentos públicos nesses gastos. Ao utilizar-se mais uma vez a regra de orçamento equilibrado, obtém-se:

$$
r \frac{B_{t-1}}{P I B_{t-1}}+\frac{G C_{1}-T_{t}}{P I B_{t}}+(\delta-\vartheta) \frac{K_{t}}{P I B_{t}}=0
$$

Ao considerar ${ }^{11} \frac{K_{t}}{P I B_{t}}-\frac{K_{t-1}}{P I B_{t-1}}=\frac{I_{t}}{P I B_{t}}-n \frac{K_{t}}{P I B_{t}}$ e substituir (5) em (2), encontra-se:

$$
\left(\frac{B_{t}}{P I B_{t}}-\frac{B_{t-1}}{P I B_{t-1}}\right)-\left(\frac{K_{t}}{P I B_{t}}-\frac{K_{t-1}}{P I B_{t-1}}\right)=-n\left(\frac{B_{t}}{P I B_{t}}-\frac{K_{t}}{P I B_{t}}\right)
$$

Isso indica que, independentemente do nível inicial da razão dívida pública/ PIB $\left(\frac{B_{i}}{P B_{i}}\right)$, eventualmente $\left(\frac{B_{i}}{P I B_{t}} \frac{K_{t}}{P B_{B_{i}}}\right) \Rightarrow 0$. Assim, ao excluir-se o investimento público líquido do cálculo do gasto governamental determinante da meta fiscal, é possível obter um crescimento na dívida pública que convirja para o crescimento do estoque de capital. Em outras palavras, desde que a variação do estoque de capital é um dos principais determinantes do crescimento do PIB, é possível elevar-se o nível do estoque de capital como proporção do PIB e não se prejudicar a estabilidade da relação dívida pública/PIB.

Nesse modelo, uma característica importante é que a dívida pública passa a ter lastro. A emissão de uma nova dívida é acompanhada por um aumento equivalente do estoque de capital. Assim, a trajetória da dívida pública é sempre sustentável, pois um aumento na dívida (passivo) gera um aumento de igual magnitude no estoque de capital (ativo).

Ainda que o modelo apresentado seja bastante intuitivo e consiga captar os principais aspectos da proposta de poupança em conta corrente do governo, possui pouca possibilidade de aplicação ou teste empírico para o Brasil, pois sua hipótese é que, ao se excluirem os investimentos públicos, o governo apresente o orçamento equilibrado período a período, que pode ser considerada uma hipótese muito forte. Portanto, deve-se trabalhar com um modelo mais flexível.

\section{METODOLOGIA}

A equação (1) mostra como a dívida pública varia de acordo com variações na taxa de juros, na taxa de crescimento econômico e no superávit primário.

\footnotetext{
${ }^{11}$ Esta consideração pode ser obtida a partir da equação-chave do modelo de crescimento econômico de Solow, ressaltando-se que, em equilíbrio, a poupança se iguala ao investimento. Além disso, na obtenção dessa equação, consideram-se nulas as taxas de crescimento populacional e a taxa de depreciação.
} 
Entretanto, ela não diz nada sobre como se relacionam essas três variáveis. Por exemplo, se aumentos na taxa de juros reduzem a taxa de crescimento econômico. Se comprovada essa hipótese, a taxa de juros tem dois efeitos sobre a dívida pública. O primeiro dado pelo aumento dos juros pagos sobre o estoque da dívida e o segundo dado pelo efeito sobre o crescimento econômico.

No caso do investimento público, essa questão é particularmente importante, pois, se esse não se relaciona com as demais variáveis, a proposta de poupança em conta corrente do governo perde sentido, sendo o investimento público um gasto como qualquer outro.

Com o intuito de verificar as principais relações entre as variáveis, utilizase a metodologia VAR, que, segundo Enders (2003), tem por objetivo captar as relações entre as variáveis. Daí essa metodologia ficar conhecida como ateórica, pois seu objetivo é tentar captar o relacionamento entre as variáveis impondo o mínimo possível de restrições.

Dessa forma, a avaliação da proposta consiste na consideração das relações entre as variáveis, com o objetivo de usar esses resultados em projeções sobre a dívida pública, quando a meta de política fiscal é o superávit primário ou a poupança em conta corrente do governo, comparando os resultados diante dessas alternativas.

Ademais, nas projeções da razão dívida pública/PIB, tanto o superávit primário quanto a poupança em conta corrente do governo são exogenamente estabelecidos conforme a vigente meta de política fiscal: $4,25 \%$ do PIB. As projeções seguem a equação (1), conforme Burnside (2004). ${ }^{12}$

\section{Análise VAR}

Nesta seção, estudam-se dois modelos de vetores auto-regressivos (VAR). Esses dois modelos contêm dados mensais de janeiro de 1999 a dezembro de 2005. O primeiro modelo contempla a dinâmica entre a taxa real de juros Selic $(r)$, superávit primário do setor público consolidado em percentual do PIB (sp), dívida líquida do setor público consolidado em percentual do PIB (div) e taxa real de crescimento do PIB $(n)$ calculada pelo Banco Central do Brasil. O segundo modelo, além de utilizar as variáveis $r$, div e $n$, separa o superávit primário em dois componentes: investimento público em percentual do PIB (inv) e poupança em conta corrente do governo em percentual do PIB (poup).

O objetivo de efetuar esta análise VAR em dois modelos deve-se à necessidade de captarem-se as diferenças dos efeitos do investimento público e da poupança em conta corrente do governo sobre a economia brasileira, quando comparados aos efeitos do superávit primário.

\footnotetext{
${ }^{12}$ A equação (1) refere-se ao superávit primário. Para a análise da poupança em conta corrente do governo, decompõe-se o superávit primário, aproximando-se da equação (2), e avalia-se o efeito do investimento sobre a dívida de acordo com as relações obtidas pelo VAR.
} 
Para que a análise VAR seja efetuada, é necessário testar a presença de raiz unitária nas variáveis do modelo. Nesse sentido, implementa-se o teste ampliado de Dickey-Fuller (ADF). De acordo com esse teste, a taxa real de juros e a taxa real de crescimento do PIB devem ser utilizadas em nível, enquanto as demais variáveis em primeira diferença (Apêndice 1).

Primeiro modelo

A partir dos critérios de Akaike (AIC), Schwarcz (SIC) e Hanna-Quin (HQ), determina-se o número de defasagens utilizadas no primeiro modelo. Os critérios AIC e HQ indicam que o uso de duas defasagens no modelo é o mais adequado, contudo o critério SIC indica a utilização de apenas uma defasagem. Dessa forma, em virtude de um maior número de critérios indicar duas defasagens, optou-se por essa especificação. O modelo estimado utiliza uma constante.

No que concerne à função de resposta a impulso, ${ }^{13}$ nota-se que o efeito dos choques das variáveis sobre si próprias é positivo e temporário. As respostas da dívida pública a choques no superávit primário, na taxa real de juros e na taxa real de crescimento econômico são desprezíveis. As respostas do superávit primário a choques na dívida pública e na taxa real de crescimento econômico não são significativas, não obstante, entre o primeiro e o oitavo mês, o superávit primário responde levemente de forma positiva a um impulso na taxa real de juros (Apêndice 2).

Entre o primeiro e o nono mês, a taxa real de juros responde positivamente a choques na dívida pública e na taxa real de crescimento econômico, todavia, em relação a um choque no superávit primário, a resposta da taxa real de juros é desprezível. Após o quinto mês, as respostas do crescimento econômico a choques na dívida pública e na taxa de juros são significativas e negativas. Por sua vez, a resposta do crescimento econômico a um impulso no superávit primário não é significativa (Apêndice 2).

Conclui-se que, em termos de contribuição para as projeções da razão dívida/ PIB, o VAR sugere que a taxa real de crescimento econômico responde negativamente à taxa real de juros.

Segundo modelo

$\mathrm{Na}$ escolha das defasagens, os critérios SIC e HQ indicam que o modelo mais adequado contém uma defasagem. Entretanto, o critério de AIC indica que o modelo adequado possui duas defasagens. Em virtude de um maior número de critérios indicar uma defasagem, ao seguir-se o critério adotado no primeiro modelo, opta-se por utilizar uma defasagem. A estimação do segundo modelo utiliza uma constante.

\footnotetext{
${ }^{13}$ A fim de efetuar a análise da função de resposta a impulso, utiliza-se o ordenamento $\mathrm{d}(d i v) \rightarrow \mathrm{d}(s p)$ $\rightarrow r \rightarrow n$.
} 
No que tange à função de resposta a impulso, ${ }^{14}$ observa-se que o efeito dos choques das variáveis sobre si próprias é positivo e temporário. As respostas da dívida pública a choques na taxa real de crescimento econômico, na taxa real de juros, na poupança em conta corrente do governo e no investimento público são desprezíveis. As respostas da poupança em conta corrente do governo a choques na dívida pública, na taxa real de crescimento econômico e no investimento público não são significativas, conquanto, entre o primeiro e o quinto mês, a poupança em conta corrente do governo responder positivamente à taxa real de juros (Apêndice 3).

As respostas do investimento público a choques na dívida pública, na taxa real de juros e na taxa real de crescimento econômico são desprezíveis. Por sua vez, entre o primeiro e o segundo mês, a resposta do investimento público a um choque na poupança em conta corrente do governo é positiva. Do primeiro ao nono mês, a taxa real de juros responde de forma positiva a choques na dívida pública e na taxa real de crescimento econômico, porém as respostas da taxa real de juros a choques na poupança em conta corrente do governo e no investimento público são desprezíveis (Apêndice 3).

Entre o quinto e o décimo segundo mês, choques na dívida pública e na taxa real de juros afetam negativamente a taxa real de crescimento econômico. Em relação a um impulso no investimento público, a resposta da taxa real de crescimento econômico é positiva do quarto ao oitavo mês. A resposta da taxa real de crescimento econômico a um impulso na poupança em conta corrente do governo é desprezível (Apêndice 3).

Conclui-se que, em termos de contribuição para as projeções da razão dívida/ PIB, o VAR indica que a taxa real de crescimento econômico responde negativamente à taxa real de juros e positivamente ao investimento público.

\section{Análise de cenários}

No intuito de efetuar-se uma análise de sustentabilidade em cenários de meta fiscal com superávit primário ou poupança em conta corrente do governo, mostramse evoluções da razão dívida pública/PIB ao longo dos próximos 10 anos utilizando as relações sugeridas pelas funções de resposta a impulso da seção anterior

Cenário básico ${ }^{15}$

Neste cenário, adota-se como hipótese a manutenção de um superávit primá-

\footnotetext{
${ }^{14}$ Com vistas a analisar a função de resposta a impulso, utiliza-se o ordenamento $\mathrm{d}($ div $) \rightarrow \mathrm{d}($ poup $) \rightarrow$ $\mathrm{d}(i n v) \rightarrow r \rightarrow n$.

${ }^{15}$ A terminologia "cenário básico" refere-se à hipótese de que a política fiscal baseada em metas de superávit primário será mantida, enquanto, nos “cenários alternativos”, a hipótese subjacente é de política fiscal baseada em metas de poupança em conta corrente do governo.
} 
rio da ordem de $4,25 \%$ do PIB e efetuam-se as simulações com base na equação ${ }^{16}$ (1). Com relação à taxa real de juros, desde que se observam patamares muito elevados (em torno de 12\%) nos últimos anos, adotam-se quatro hipóteses: $12 \%$, $11 \%, 10 \%$ e $9 \%$ e, em conseqüência disso, quatro hipóteses de taxa real de crescimento econômico: $2,5 \%, 2,7 \%, 3 \%$ e $3,2 \%$, respectivamente.

A Tabela 1 apresenta os resultados das simulações embasadas no cenário básico, sugerindo que apenas nos estados da natureza mais pessimistas, com taxas reais de juros de $13 \%$ e $12 \%$ e taxas reais de crescimento econômico de $2,3 \%$ e $2,5 \%$, respectivamente, obtém-se uma aceleração da dívida pública. No terceiro estado da natureza, no decorrer dos próximos 10 anos, com taxa real de juros de $11 \%$ e taxa real de crescimento econômico de $2,7 \%$, há uma estabilização da relação dívida pública/PIB em torno de $50 \%$. No quarto, com taxa real de juros de $10 \%$ e taxa real de crescimento econômico de $3 \%$, a relação dívida/PIB alcança o nível de $48 \%$ nos próximos três anos e atinge o nível de aproximadamente $44 \%$ daqui a 10 anos. Por fim, no sexto estado da natureza, com taxa real de juros de $8 \%$ e taxa real de crescimento econômico de $3,5 \%$, a relação dívida pública/PIB entra em sua trajetória mais descendente e, em 10 anos, aproxima-se dos $31 \%$.

Tabela 1: Simulações para a dívida pública

\begin{tabular}{|c|c|c|c|c|}
\hline & $\mathrm{T}+1$ & $\mathrm{~T}+3$ & $\mathrm{~T}+6$ & $\mathrm{~T}+10$ \\
\hline $\mathrm{r}=13 \% ; n=2,3 \%$ & $52,20 \%$ & $54,62 \%$ & $58,24 \%$ & $63,07 \%$ \\
\hline$r=12 \% ; n=2,5 \%$ & $51,59 \%$ & $52,78 \%$ & $54,57 \%$ & $56,95 \%$ \\
\hline$r=11 \% ; n=2,7 \%$ & $50,98 \%$ & $50,94 \%$ & $50,89 \%$ & $50,83 \%$ \\
\hline$r=10 \% ; n=3,0 \%$ & $50,32 \%$ & $48,96 \%$ & $46,92 \%$ & $44,20 \%$ \\
\hline$r=9 \% ; n=3,2 \%$ & $49,70 \%$ & $47,12 \%$ & $43,24 \%$ & $38,08 \%$ \\
\hline$r=8 \% ; n=3,5 \%$ & $49,04 \%$ & $45,13 \%$ & $39,27 \%$ & $31,45 \%$ \\
\hline
\end{tabular}

Fonte: Elaborada pelos autores.

\section{Cenários alternativos}

A fim de separar o investimento público do superávit primário e verificar a evolução da dívida pública de acordo com o conceito de poupança em conta corrente do governo, constroem-se seis cenários alternativos com diferentes estados da natureza em cada um deles.

A primeira consideração refere-se às receitas financeiras oriundas do retorno do investimento, representada pelo termo $v k$ na equação (2). Para efeitos de si-

\footnotetext{
${ }^{16}$ Em uma breve comparação com os cálculos apresentados por Goldfajn (2002), cabe destacar que não se considera o ajuste patrimonial no cálculo da trajetória da razão dívida pública/PIB. Assim, por exemplo, não se leva em consideração o possível aparecimento de "esqueletos" ao longo do tempo. Contudo, caso seja considerado o aparecimento de "esqueletos", a única diferença encontra-se nos níveis dos resultados apresentados, i.e., não há alterações das trajetórias da razão dívida pública/PIB.
} 
mulação, adota-se que $v$ é igual a zero, i.e., o termo $v k$ é nulo. Duas são as justificativas para a nulidade desse termo: em primeiro lugar, é válido mencionar que, diferentemente do setor privado, a grande maioria dos investimentos públicos não gera receita financeira direta ao governo; em segundo, as receitas oriundas do retorno dos investimentos, quando existem, já são contabilizadas como receita não financeira e, portanto, contabilizadas no cálculo do superávit primário. ${ }^{17}$

Com relação às simulações da equação (2), a segunda consideração refere-se ao termo investimento. De acordo com a Lei 4.320/64, o investimento realizado com o intuito de repor o estoque de capital é contabilizado na rubrica inversão financeira, podendo até mesmo ser contabilizado como despesa de custeio. Dessa forma, a depreciação do capital público está incluída no gasto corrente, ou seja, o volume de investimento refere-se, em sua totalidade, a investimentos líquidos.

$\mathrm{Na}$ construção dos seis cenários alternativos, definem-se como ponto de partida seis hipóteses para a taxa real de juros $\left(\mathrm{r}_{0}\right): 13 \%, 12 \%, 11 \%, 10 \%, 9 \%$ e $8 \%$. Nesses cenários, a suposição básica é que a implementação do conceito de poupança em conta corrente do governo não implique qualquer redução na austeridade fiscal perseguida pelo governo brasileiro nos últimos anos.

Essa manutenção da vigente austeridade fiscal pode ser feita da seguinte forma: desde que, de janeiro de 1999 a junho de 2005, a média de investimento do setor público consolidado é aproximadamente $3,40 \%$ do PIB, ao excluir esse investimento da meta de superávit primário do setor público consolidado obtém-se uma poupança em conta corrente do governo de $7,65 \%$ do PIB, que será a proposição de meta de política fiscal, pois equivale a um esforço fiscal de um superávit primário igual a $4,25 \%$ do PIB. Dessa forma, a implementação de uma meta fiscal embasada no conceito de poupança em conta corrente do governo não implica qualquer diminuição na austeridade fiscal.

Assim, no decorrer dos próximos 10 anos, a partir da implementação dessa meta de poupança em conta corrente do governo, consideram-se para cada um dos seis cenários alternativos quatro distintos estados da natureza para o investimento público: o primeiro considera um volume de investimento público de $3,80 \%$ do PIB; o segundo, 4,20\% do PIB; o terceiro, 4,60\% do PIB; o último, $5 \%$ do PIB. É válido repisar que, conforme as previsões das funções de resposta a impulso, elevação no investimento público implica aumento na taxa real de crescimento econômico, de modo que, a partir da hipótese inicial para a taxa real de juros $\left(\mathrm{r}_{0}\right)$, a taxa real de crescimento econômico eleva-se simultaneamente à elevação do investimento.

No primeiro cenário alternativo (Tabela 2), adota-se a hipótese inicial de taxa real de juros de $13 \%$ ao ano, de modo que, a partir das sucessivas elevações dos investimentos públicos situados em 3,80\% do PIB até $5 \%$ do PIB, obtêm-se eleva-

\footnotetext{
${ }^{17}$ Por exemplo, na construção de estradas, não há receita financeira. No entanto, caso o governo faça um determinado tipo de concessão ao setor privado, essa estrada pode até gerar uma receita nãofinanceira para o governo, a qual será contabilizada no superávit primário.
} 
ções na taxa real de crescimento econômico de 2,2\% até 3,0\%, respectivamente. Em conformidade com os aumentos do investimento público e da taxa real de crescimento econômico, supõem-se sucessivas reduções nas taxas reais de juros de $12,38 \%$ até $10,55 \%$, respectivamente.

Nesse caso, os resultados indicam que dívida pública não é sustentável e que aumentos no investimento público podem elevar a dívida pública. Em outras palavras, o efeito benéfico sobre o investimento público não compensa a pressão que ele exerce sobre as finanças do setor público. É válido ressaltar que, com taxas reais de juros de $13 \%$, mesmo no caso do superávit primário, conforme exposto na Tabela 1 , a dívida pública é explosiva ao longo do tempo. De forma similar, ocorre no cenário em que a taxa de juros inicia em $12 \%$ (Tabela 3 )

Tabela 2: Simulações para a dívida pública em um cenário de implementação de meta fiscal baseada na poupança em conta corrente do governo, com sucessivas elevações do investimento público

\begin{tabular}{|c|c|c|c|c|}
\hline$r_{0}=13 \%$ & $T+1$ & $T+3$ & $T+6$ & $T+10$ \\
\hline$r=12,38 \% ; n=2,2 \%$ & $52,34 \%$ & $55,03 \%$ & $59,07 \%$ & $64,46 \%$ \\
\hline$r=11,77 \% ; n=2,4 \%$ & $52,33 \%$ & $54,99 \%$ & $58,99 \%$ & $64,32 \%$ \\
\hline$r=11,16 \% ; n=2,6 \%$ & $52,31 \%$ & $54,95 \%$ & $58,90 \%$ & $64,18 \%$ \\
\hline$R=10,55 \% ; n=3,0 \%$ & $52,20 \%$ & $54,60 \%$ & $58,21 \%$ & $63,02 \%$ \\
\hline
\end{tabular}

Fonte: Elaborada pelos autores.

Tabela 3: simulações para a dívida pública em um cenário de implementação de meta fiscal baseada na poupança em conta corrente do governo, com sucessivas elevações do investimento público

\begin{tabular}{|c|c|c|c|c|}
\hline$r_{0}=12 \%$ & $T+1$ & $T+3$ & $T+6$ & $T+10$ \\
\hline$r=11,43 \% ; n=2,5 \%$ & 51,70 & 53,11 & 55,22 & 58,04 \\
\hline$r=10,87 \% ; n=2,7 \%$ & 51,71 & 53,15 & 55,30 & 58,16 \\
\hline$r=10,30 \% ; n=3,0 \%$ & 51,63 & 53,01 & 55,03 & 57,73 \\
\hline$r=9,74 \% ; n=3,2 \%$ & 51,68 & 53,05 & 55,11 & 57,85 \\
\hline
\end{tabular}

Fonte: Elaborada pelos autores.

No terceiro cenário alternativo (Tabela 4), a hipótese inicial é de taxa real de juros de $11 \%$, caso não haja elevação nos investimentos públicos. Com as sucessivas elevações dos investimentos públicos de 3,8\%, 4,2\%, 4,6\% até 5,0\%, obtêm-se taxas reais de crescimento econômico: 2,7\%, 3,0\%, 3,2\% e 3,5\%, respectivamente. Em conformidade com esses valores maiores para a taxa real de crescimento econômico, realizam-se ajustes (para baixo) nas taxas reais de juros de $10,48 \%, 9,96 \%, 9,44 \%$ até $8,92 \%$, respectivamente.

Nesse caso, nos quatro estados da natureza, os resultados indicam que há uma estabilização na razão dívida pública/PIB ao longo do tempo. Nos próximos 10 anos, em qualquer um dos estados da natureza, a dívida pública se eleva em cerca de $1 \%$. 
Tabela 4: Simulações para a dívida pública em um cenário de implementação de meta fiscal baseada na poupança em conta corrente

do governo, com sucessivas elevações do investimento público

\begin{tabular}{|c|c|c|c|c|}
\hline$r_{0}=11 \%$ & $T+1$ & $T+3$ & $T+6$ & $T+10$ \\
\hline$r=10,48 \% ; n=2,7 \%$ & 51,11 & 51,35 & 51,70 & 52,17 \\
\hline$R=9,96 \% ; n=3,0 \%$ & 51,09 & 51,29 & 51,59 & 51,99 \\
\hline$R=9,44 \% ; n=3,2 \%$ & 51,13 & 51,39 & 51,79 & 52,32 \\
\hline$R=8,92 \% ; n=3,5 \%$ & 51,11 & 51,34 & 51,68 & 52,14 \\
\hline
\end{tabular}

Fonte: Elaborada pelos autores.

No quarto cenário alternativo (Tabela 5), a hipótese inicial é de taxa real de juros de $10 \%$, caso não haja elevação nos investimentos públicos. Isso significa que, caso o investimento público eleve-se para $3,8 \%, 4,2 \%, 4,6 \%$ até $5 \%$, obtêmse taxas reais de crescimento do PIB de $3 \%, 3,2 \%, 3,5 \%$ até $3,7 \%$, respectivamente. Novamente, em virtude das maiores taxas reais de crescimento econômico, implementam-se ajustes (para baixo) nas taxas reais de juros de 9,52\%, 9,05\%, $8,58 \%$ até $8,11 \%$, respectivamente.

$\mathrm{Na}$ Tabela 5, nos quatro estados da natureza, nos próximos 10 anos, os resultados mostram que a dívida pública reduz-se e atinge entre $45 \%$ e $47 \%$ do PIB, dependendo da taxa de crescimento do PIB e do volume de investimento público a ser realizado. De igual forma, no quinto e no sexto cenário alternativo, a dívida pública continua em trajetória descendente (Tabelas 6 e 7).

Tabela 5: Simulações para a dívida pública em um cenário de implementação de meta fiscal baseada na poupança em conta corrente do governo, com sucessivas elevações do investimento público

\begin{tabular}{|c|c|c|c|c|}
\hline$r 0=10 \%$ & $T+1$ & $T+3$ & $T+6$ & $T+10$ \\
\hline$r=9,52 \% ; n=3,0 \%$ & 50,47 & 49,42 & 47,85 & 45,75 \\
\hline$r=9,05 \% ; n=3,2 \%$ & 50,53 & 49,60 & 48,20 & 46,35 \\
\hline$r=8,58 \% ; n=3,5 \%$ & 50,54 & 49,62 & 48,24 & 46,40 \\
\hline$r=8,11 \% ; n=3,7 \%$ & 50,59 & 49,79 & 48,59 & 46,99 \\
\hline
\end{tabular}

Fonte: Elaborada pelos autores.

Tabela 6: Simulações para a dívida pública em um cenário de implementação de meta fiscal baseada na poupança em conta corrente

do governo, com sucessivas elevações do investimento público

\begin{tabular}{|c|c|c|c|c|}
\hline $\mathrm{r} 0=9 \%$ & $\mathrm{~T}+1$ & $\mathrm{~T}+3$ & $\mathrm{~T}+6$ & $\mathrm{~T}+10$ \\
\hline $\mathrm{r}=8,57 \% ; n=3,2 \%$ & $49,89 \%$ & $47,67 \%$ & $44,35 \%$ & $39,92 \%$ \\
\hline$r=8,15 \% ; n=3,7 \%$ & $49,82 \%$ & $47,46 \%$ & $45,10 \%$ & $39,21 \%$ \\
\hline$r=7,72 \% ; n=3,9 \%$ & $49,90 \%$ & $47,70 \%$ & $44,41 \%$ & $40,03 \%$ \\
\hline$r=7,30 \% ; n=4,1 \%$ & $49,98 \%$ & $47,95 \%$ & $44,91 \%$ & $40,85 \%$ \\
\hline
\end{tabular}

Fonte: Elaborada pelos autores. 
Tabela 7: Simulações para a dívida pública em um cenário de implementação de meta fiscal baseada na poupança em conta corrente do governo, com sucessivas elevações do investimento público

\begin{tabular}{|c|c|c|c|c|}
\hline$r_{0}=8 \%$ & $T+1$ & $T+3$ & $T+6$ & $T+10$ \\
\hline$r=7,62 \% ; n=3,9 \%$ & $49,04 \%$ & $45,14 \%$ & $39,29 \%$ & $31,49 \%$ \\
\hline$r=7,24 \% ; n=4,1 \%$ & $49,15 \%$ & $45,46 \%$ & $39,93 \%$ & $32,55 \%$ \\
\hline$r=6,87 \% ; n=4,3 \%$ & $49,26 \%$ & $45,78 \%$ & $40,56 \%$ & $33,61 \%$ \\
\hline$r=6,49 \% ; n=4,5 \%$ & $49,37 \%$ & $46,10 \%$ & $41,20 \%$ & $34,67 \%$ \\
\hline
\end{tabular}

Fonte: Elaborada pelos autores.

Nesta seção, os resultados apresentados sugerem que a implementação de uma meta fiscal embasada na poupança em conta corrente do governo, com sucessivas elevações no investimento público, não torna a política fiscal irresponsável nem coloca a relação dívida pública/PIB em uma trajetória explosiva.

É válido ressaltar que, com taxas reais de juros maiores ou iguais a $12 \%$ ao ano, tanto o superávit primário de $4,25 \%$ do PIB quanto a poupança em corrente do governo de $7,65 \%$ do PIB coloca a razão dívida pública/PIB em uma trajetória explosiva. De forma análoga, com taxas reais de juros menores ou iguais a $10 \%$ ao ano, nos próximos 10 anos, tanto o superávit primário de 4,25\% do PIB quanto a poupança em conta corrente do governo de $7,65 \%$ do PIB torna a relação dívida pública/PIB descendente.

Assim, a elevação propiciada no volume de investimento público implica aumento na taxa real de crescimento da economia, indicando, portanto, um potencial aumento no bem-estar da população brasileira.

\section{IMPLEMENTAÇÃO DA POUPANÇA EM CONTA CORRENTE DO GOVERNO}

Para que se implemente uma meta fiscal baseada na poupança em conta corrente do governo, cabe desmistificar duas questões. A primeira questão que deve ser desmistificada refere-se ao fato de essa política significar ou não um relaxamento fiscal. A pergunta objetiva é: ao adotar-se meta fiscal baseada na poupança em conta corrente do governo, em vez de meta de superávit primário, a relação dívida pública/PIB entra em uma trajetória explosiva?

Em um primeiro momento, pode-se ter a impressão de que o objetivo da implementação da poupança em conta corrente do governo é relaxar a política fiscal e retomar a antiga trajetória de instabilidade. No entanto, no decorrer da última seção, mostra-se que, com relação à sustentabilidade da relação dívida pública/ PIB, no caso da implementação da meta fiscal baseada na poupança em conta corrente do governo, a trajetória da relação dívida pública/PIB é basicamente idêntica à obtida com a meta fiscal baseada no superávit primário. 
A segunda questão a ser desmistificada refere-se aos procedimentos operacionais para que a proposta de meta fiscal baseada na poupança em conta corrente do governo seja factível e implementável. A pergunta objetiva é: com relação à equação 2 , na operacionalização do conceito de poupança em conta corrente do governo, como impedir a confusão burocrática entre gastos correntes $G_{t} \mathrm{e}$ investimentos $I_{t}$ ? Haja vista alguém sugerir que a operacionalização do conceito de poupança em corrente do governo significa uma janela de oportunidades para os gestores transformarem gastos correntes em investimento, burlando, pois, a meta fiscal.

Entende-se, contudo, que essa janela de oportunidades pode ser exaurida com relativa facilidade. Em primeiro lugar, no governo federal, no Ministério da Fazenda, a Secretaria do Tesouro Nacional (MF/STN) possui uma Coordenação Geral de Análise Econômico-Fiscal de Projetos de Investimento Público que, entre outras atribuições, dedica-se a avaliar e acompanhar os investimentos realizados por meio de Parceria Público-Privada. Ora, de posse dessa atribuição, nota-se que essa Coordenação é plenamente capaz de avaliar ou diferenciar quais se enquadram como gastos correntes e quais despesas devem ser enquadradas como investimento.

Desde que esse arcabouço institucional se situa dentro do próprio governo federal, um outro possível argumento é que esse órgão tende a sofrer pressões “políticas”. Dessa maneira, o processo de decisão do que é investimento pode não ser suficientemente transparente, de modo a basear-se em critérios exclusivamente econômicos. Duas soluções simples apresentam-se para essa possibilidade: i) incluir na Lei de Responsabilidade Fiscal (LRF) penalidades severas para o gestor que propositadamente indicar gasto corrente como investimento; ii) na LRF, com relação ao acompanhamento e fiscalização da implementação da poupança em conta corrente do governo, incluir recomendações ao Tribunal de Contas da União (TCU), órgão externo ao poder executivo e responsável pela fiscalização do gasto federal.

No que concerne aos governos estaduais e municipais, estruturas similares à Coordenação Geral instituída no MF/STN podem ser implementadas. Além disso, as fiscalizações externas devem ser atribuídas aos Tribunais de Contas responsáveis pelos gastos estaduais e municipais, respectivamente. É claro que a inclusão dos normativos de punições na LRF é válida para todos os entes da Federação.

Assim sendo, não existem empecilhos práticos que possam comprometer a adoção do conceito de poupança em conta corrente do governo como instrumento de política fiscal.

\section{CONCLUSÕES}

Ao longo deste artigo, objetiva-se avaliar os impactos na sustentabilidade da relação dívida pública/PIB de uma eventual mudança na prática da política fiscal 
adotada no Brasil. Em termos práticos, essa mudança significa implementar uma meta fiscal que exclua os investimentos públicos do cálculo do superávit primário. Em teoria, isso implica uma alteração na meta fiscal a ser perseguida pelo governo brasileiro, ou seja, acarreta a permuta do conceito de superávit primário pelo conceito de poupança em conta corrente do governo.

Os resultados indicam que essa permuta não resulta em qualquer alteração substancial na trajetória intertemporal da relação dívida pública/PIB. De acordo com os cenários traçados, construídos a partir das relações obtidas em funções de resposta a impulso, a trajetória de sustentabilidade da relação dívida pública/PIB é similar tanto no uso do conceito de superávit primário quanto na utilização do conceito de poupança em conta corrente do governo.

Além disso, evidencia-se que, em nível federal, a implementação da poupança em conta corrente do governo não traz quaisquer problemas operacionais. Haja vista que existe uma Coordenação no MF/STN que já contém suficiente conhecimento para diferenciar de forma precisa os investimentos públicos dos gastos correntes. Nos níveis estaduais e municipais, estruturas similares à instituída no MF/ STN devem ser implementadas. Ademais, de forma similar às funções atribuídas ao TCU na implementação da poupança em conta corrente do governo em nível federal, a fiscalização e o acompanhamento da implementação da poupança em conta corrente do governo nos níveis estaduais e municipais devem ser atribuídos aos Tribunais de Contas responsáveis pelos respectivos entes da federação.

Por fim, vale mencionar que, apesar de a implementação da poupança em conta corrente do governo não trazer substancial alteração na trajetória da relação dívida pública/PIB, esse novo conceito pode contribuir para o aumento da taxa real de crescimento da economia brasileira, elevando, pois, o bem-estar da sociedade brasileira.

\section{REFERÊNCIAS BIBLIOGRÁFICAS}

Afonso, J. R., Amorim, E., Biasoto Jr., G. "Fiscal space and public sector investments in infrastructure: a Brazilian case-study". Ipea, 2005 (Texto para Discussão, 1.141).

Almeida, M., Pessoa, S. Análise dos gastos públicos não-financeiros do governo federal - 2001 a 2006. (Nota Técnica, fevereiro de 2006).

Arida, P., Bacha, E. and Lara-Resende, A. (2004). "Credit, interest, and jurisdictional uncertainty: conjectures on the case of Brazil”, Instituto de Estudos de Política Econômica, Casa das Garças, Rio de Janeiro, Brasil: mimeo.

Bicalho, A. (2005). "Teste de Sustentabilidade e Ajuste Fiscal no Brasil Pós-Real. Fundação Getulio Vargas, EPGE, dissertação de mestrado.

Blanchard, O. J., Giavazzi, F. (2004). "Improving the SGP through a proper accounting of public investment”, Discussion Paper Series, $n^{\circ}$ 4.220, Centre for Economic Policy Research.

Bohn, H. (1991). " Budget balances through revenue or spending adjustments? Some historical evidence for the United States. Journal of Monetary Economics, vol. 27, pp. 333-359.

Bohn, H. (1998). “The Behavior of U. S. Public Debt and Deficits”, Quarterly Journal of Economics, vol. 113, pp. 949-963. 
Burnside, Craig (2004). “Assessing New Approaches to Fiscal Sustainability Analysis,” manuscript, Duke University, 2004.

Enders, W. (2003). “Applied Econometric Time Series”. Wiley, IE.

Giambiagi, F., Ronci, M. (2004). "Fiscal policy and debt sustainability: Cardoso's Brazil, 1995-2002”, IMF Working Paper No. 04/156, International Monetary Fund, Washington, D.C.

Goldfajn, I. (2002). “ Há razões para duvidar de que a dívida pública no Brasil é sustentável”, nota técnica $\mathrm{n}^{\circ} 25$ do BCB.

Gonçalves, F. M., Holland, M., Spacov, A. D. (2005). "Can jurisdictional uncertainty and capital controls explain the high level of real interest rates in Brazil? Evidence from panel data", mimeo.

Gremaud, A., Vasconcellos, M. A. S., Toneto Jr., R. (2005). Economia Brasileira Contemporânea, Editora Atlas, $6^{\circ}$ edição.

Hakkio, C., Rush, M. (1991). “Is the budget deficit too large?” Economic Inquiry, vol. XXIX, pp. 429-445.

Issler, J., L. Lima (2000). "Public Debt Sustainability and Endogenous Seignorage in Brazil: Time Series Evidence from 1947-92”. Journal of Development Economics, vol. 62(1), pp. 131-147.

Mello, L. (2005). "Estimating a Fiscal Reaction Function: The Case of Debt Sustainability in Brazil", OECD Economics Department Working Paper No. 423, OECD, Paris.

Ministério do Planejamento, Orçamento e Gestão, Secretaria de Orçamento Federal - SOF. "Vinculações de Receitas dos Orçamentos Fiscal e da Seguridade Social e o Poder Discricionário de Alocação dos Recursos do Governo Federal”, vol. 1, n. 1, 2003.

Musgrave, R. A. (1939). "The nature of budgetary balance and the case for the capital budget". American Economic Review, 29, 260-271.

Rocha, F. (1997). "Long-run limits on the Brazilian government debt". Revista Brasileira de Economia, vol. 51 (4), pp. 447-470.

Wilcox, D. (1989). "The sustainability of government deficits: implications of the present-value borrowing constraint”. Journal of Money, Credit and Banking, vol. 21, pp. 291-306.

\section{APÊNDICE 1}

Teste de raiz unitária ampliado de Dickey-Fuller

\begin{tabular}{|l|c|c|c|c|}
\hline Hipótese nula & Lags & SIC & Estatística $t$ & Probabilidade \\
\hline$r$ possui raiz unitária & 0 & 3,17 & $-2,95$ & 0,00 \\
\hline div possui raiz unitária & 1 & 3,39 & 0,01 & 0,68 \\
\hline$d($ div) possui raiz unitária & 0 & 3,34 & $-11,64$ & 0,00 \\
\hline sp possui raiz unitária & 0 & $-0,21$ & 1,29 & 0,94 \\
\hline$d($ sp) possui raiz unitária & 0 & $-0,23$ & $-7,27$ & 0,00 \\
\hline inv não possui raiz unitária & 0 & $-1,54$ & $-1,71$ & 0,41 \\
\hline$d($ inv $)$ não possui raiz unitária & 0 & $-1,71$ & $-5,80$ & 0,00 \\
\hline poup não possui raiz unitária & 0 & $-0,19$ & $-2,15$ & 0,22 \\
\hline$d($ poup) não possui raiz unitária & 0 & $-0,12$ & $-8,02$ & 0,00 \\
\hline$n$ não possui raiz unitária & 1 & 1,83 & $-1,61$ & 0,09 \\
\hline
\end{tabular}

Fonte: Elaborado pelos autores. 


\section{APÊNDICE 2}

Função Resposta a Impulso: $d(d i v) \rightarrow d(s p) \rightarrow r \rightarrow n$

Resposta à Inovação de \pm 2 D.P.
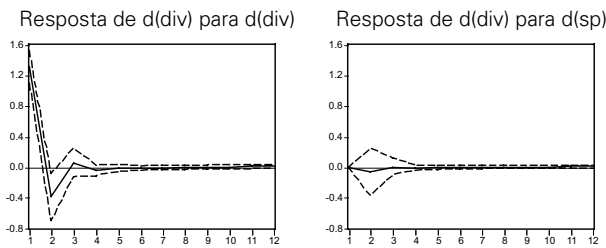

Resposta de d(div) para $r$

Resposta de d(div) para $\mathrm{n}$

Resposta de d(sp) para d(div)

Resposta de d(sp) para d(sp)
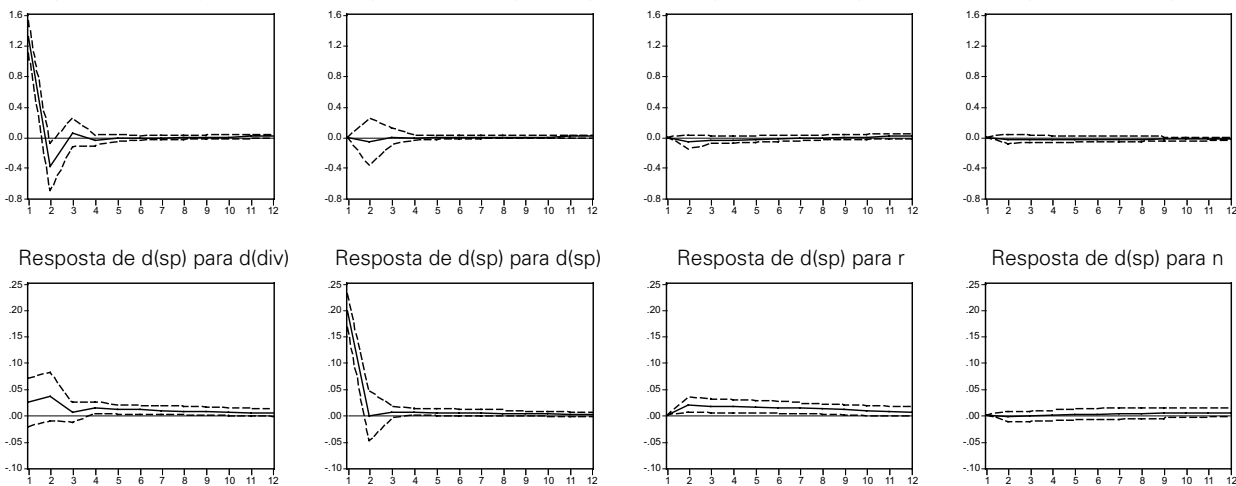

Resposta de d(sp) para $\mathrm{n}$
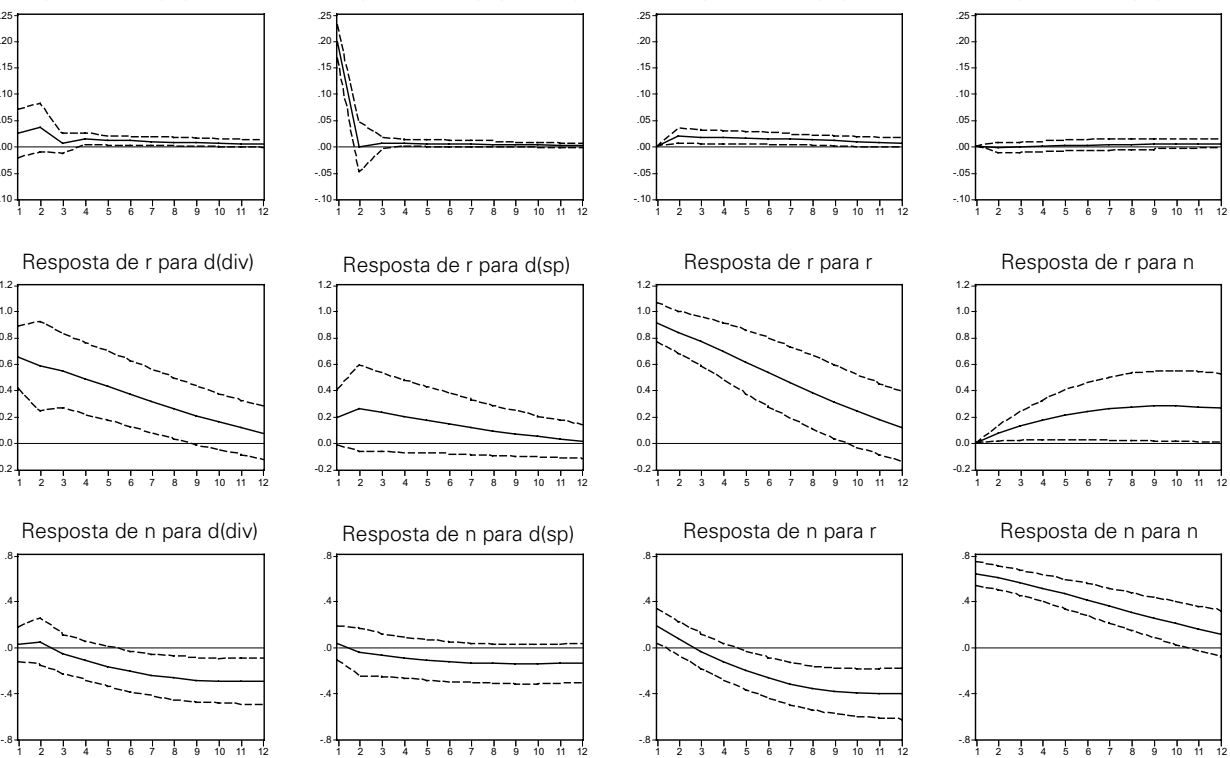

Fonte: Elaborado pelos autores.

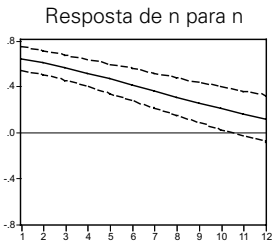




\section{APÊNDICE 3}

Função Resposta a Impulso: $d($ div $) \rightarrow d($ poup $) \rightarrow d($ inv $) \rightarrow r \rightarrow n$

Resposta à Inovação de \pm 2 D.P.
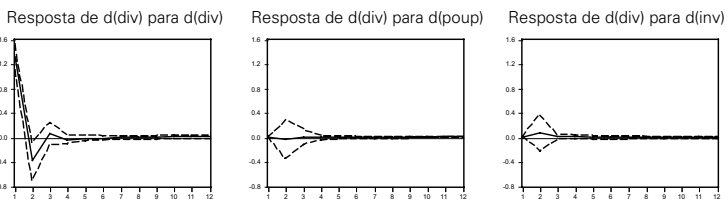

Resposta de d(div) para r

Resposta de d(div) para n

Resposta de d(poup) para d(div) Resposta de d(poup) para d(poup) Resposta de d(poup) para d(inv)
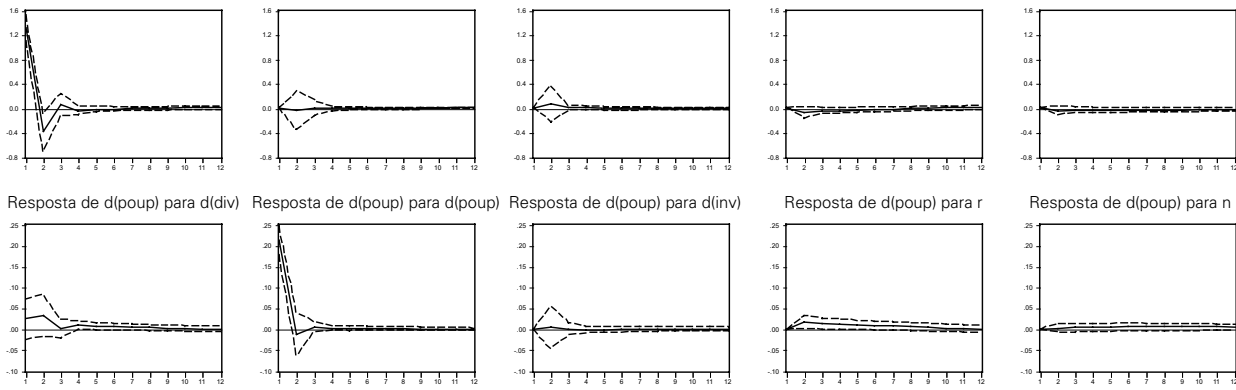

Resposta de d(poup) para r

Resposta de d(poup) para $\mathrm{n}$

Resposta de d(inv) para d(div)

Resposta de d(inv) para d(poup)

Resposta de d(inv) para d(inv)
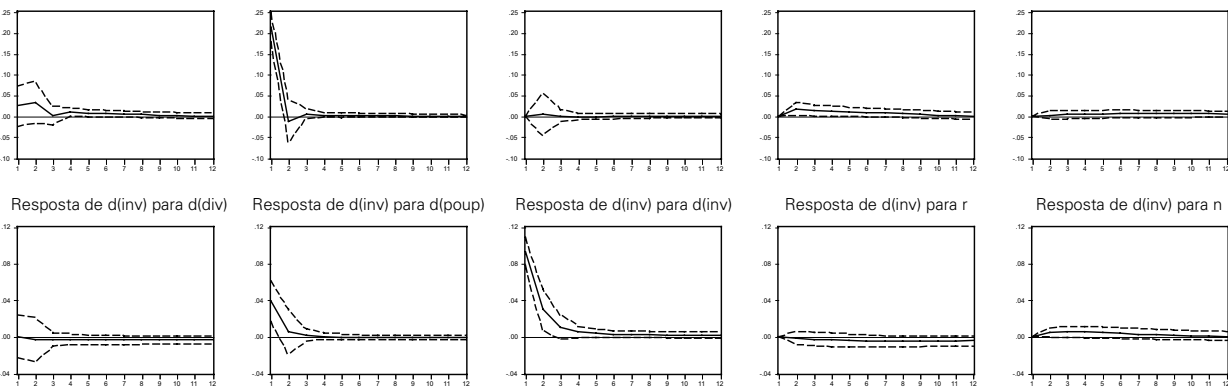

Resposta de d(inv) para $r$

Resposta de d(inv) para $n$
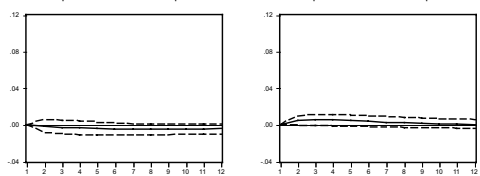

Resposta de r para d(div)

Resposta de r para d(poup)

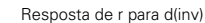

Resposta de r para r

Resposta de r para $\mathrm{n}$
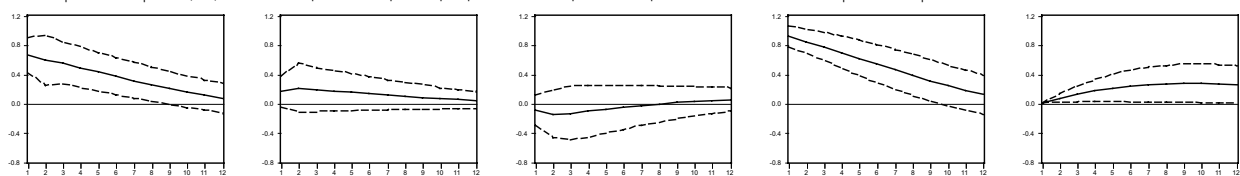

Resposta de n para d(div)

Resposta de $n$ para d(poup)

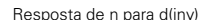

Resposta de $n$ para

Resposta de $n$ para $n$
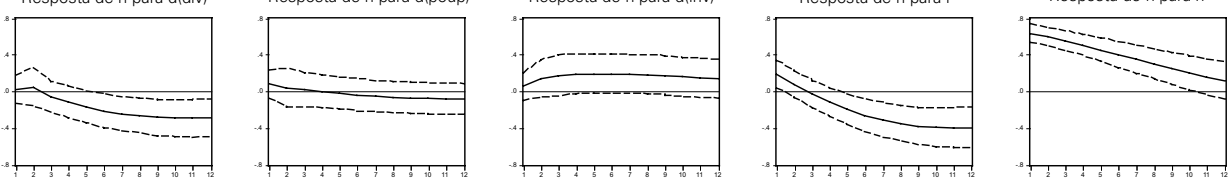

Fonte: Elaborado pelos autores. 